\title{
Digital Transformation in Warehouse Management Systems (WMS) Implementations
}

\author{
Natesan Andiyappillai \\ Senior Business Analyst, \\ NFI Industries, \\ 2 Cooper Street, \\ Camden, NJ 08102, USA
}

\begin{abstract}
Organizations have realized the importance of the Logistics channel in a Supply Chain as it plays a critical role in gaining the competitive advantage for their businesses, especially in the current highly competitive and challenging business environment. And, Warehouse Management Systems (WMS) is being one of the important and critical IT systems that helps the Logistics business to be visible and transparent for all the stakeholders in a business, thus gaining the advantage. As it evolves the technological developments in the market in the last decade or so, it has huge impact on the IT systems and WMS has no exception to it. Logistics businesses have been adopting these digital technologies to cope up with the technological advancements which helps to meet the customer expectations and requirements efficiently and thus help to provide the better customer service. This research article details out the digital technological transformation that has happened in the past decade in the Logistics business, in WMS implementations in particular, by conducting a case study in a leading Logistics and Supply Chain company.
\end{abstract}

\section{Keywords}

Warehouse Management System, WMS, Digital Transformation and Digital Technologies.

\section{INTRODUCTION}

Supply chain management is all about managing all the business partners involved in a business as they intend to work very closely to deliver the results effectively and efficiently. The Supply chain management concept arose from the Manufacturing where it was a challenge to manage the materials flow from one business partner to another. And, the primary objective of a Supply Chain was to get the materials delivered from the supplier to consumer with the right product, right quality and at the right time. A typical supply chain model is shown below to understand the major entities or components involved as an example.

It is clear that the businesses have been emerging or started to emerge onto their supply chain to make it lean and fast to meet the customer expectations. And, bringing the visibility of the supply chain to all their business partners is important to achieve that expectations.

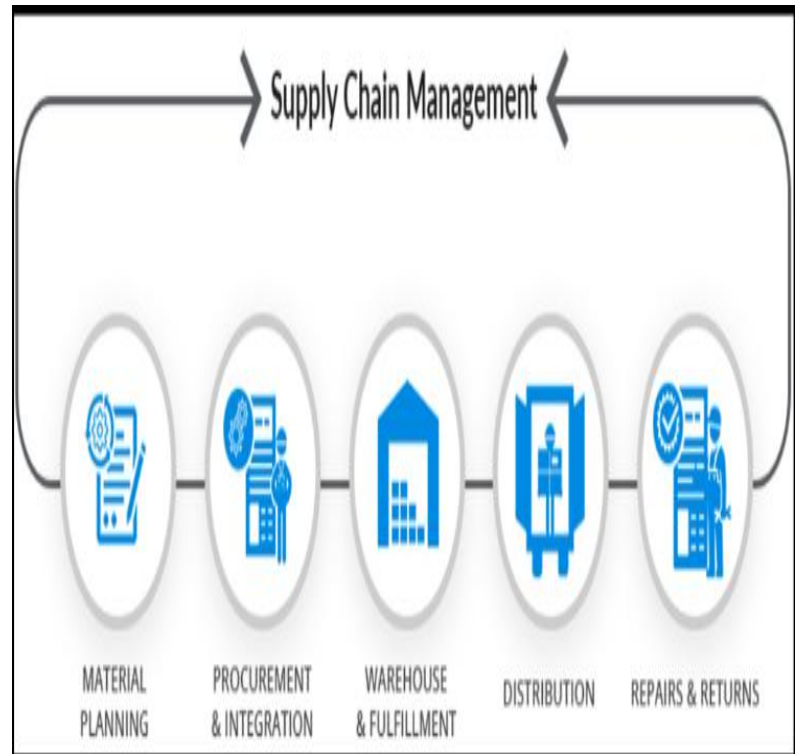

Fig 1. A Typical Supply Chain Model (source: Iron Systems Inc)

One of the key business entity in a Supply chain is the Logistics which helps greatly in meeting the customer expectations on the Warehousing and Distribution arena. As it can be seen in the below Logistics model diagram, it is a core and integral component in a Supply Chain which helps an enterprise to achieve the objective of a Supply chain. The primary activities in a Logistics channel are shown below and these activities can be carried out together by the same business partner or can be managed separately by individual business partner as it depends upon entirely on the nature and requirements of the service provider.

Each of these business entities contribute to the logistics channel in a business to maintain the inventory accurately and fulfill the customer requirements efficiently. And, when the logistics business model becomes much complex, it becomes very tedious and almost impossible to run the business with no IT capabilities.

Warehouse Management Systems (WMS) is one the key and important Logistics and Supply Chain applications that help the businesses to track and trace the inventory effectively, which ultimately helps them to evolve as a leader in the logistics and supply chain market compared to the ones who do not use the IT or WMS applications. 


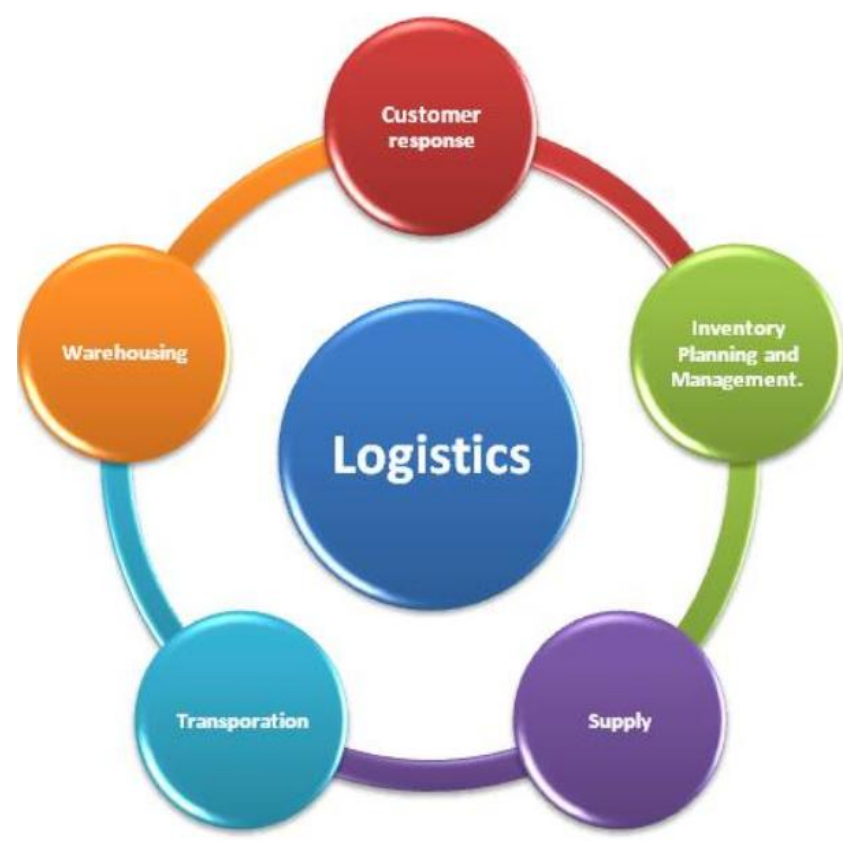

Fig 2. A Typical Logistics Model (source: wordpress.com)

The major functions within WMS are; Receiving, Putaway, Picking \& Packing, Shipping, Cycle count and Replenishment. And, managing these functions in a business with no IT or WMS application becomes impossible when the customer expectation is to manage the entire supply chain process real-time and instantaneous.

Warehouse Management System can be selected based on the business and customer requirements as there are many in the market and choosing and implementing the right one is critical for the success of the business.

As it can be seen, there have many new technologies been evolved in the market in the last decade or so in general and these digital technologies are helping the businesses and changing the traditional way of doing any business and Logistics and Supply chain has no exception to it. The key here is to evaluate if and which technology is suitable for the business and get it implemented with the right strategy.

Very interestingly, the IT product companies have been taking advantage of these technologies and getting them implemented onto their IT applications. Thus helps the businesses to advance their IT capabilities which has a great impact on their logistics and supply chain to keep them seamless.

Hence, it is important to understand the impact of these latest digital technological developments on the Logistics and Supply Chain, WMS implementations in particular, by conducting a real-time study which is attempted in this research article.

\section{LITERATURE REVIEW}

MIT Center for Digital Business and Capgemini Consulting (2011) [1] revealed on their research that the Companies in all industries and regions are experimenting with - and benefiting from - digital transformation. And, they also had added that the digital technology provides a wealth of opportunity to those willing to change their businesses to take advantage of it. And, their research results conclude that the Globalization is dictating efficient integration of businesses which can only be achieved through digital processes and collaborative tools. This shows evidently that the logistics and supply chain providers are changing their mind set to move towards the digitalization. WEF (2016) [2] reported that the digital transformation of the logistics industry is already under way and a number of suggested concrete investments in digital capabilities that will form the building blocks of a successful digital logistics business follow. Their analysis also tell us that the there is a $\$ 1.5$ trillion of value at stake for logistics players and $\$ 2.4$ trillion impact on the society as a result of digital transformation of the industry through 2025 . By looking at the number, the author could see the impact of the digital transformation on the market and on the society in the coming years. PwC (2016) [3] clearly cautions that the Supply chains are extremely complex organisms, and no company has yet succeeded in building one that's truly digital. Indeed, many of the applications required are not yet widely used. But this will change radically over the next five to 10 years, with different industries implementing systems at varying speeds. And, they envision that the real goal will be the many new business models and revenue streams the digital supply chain will open up. And, it is going to greatly benefit almost everyone in the community. Marzenna Cichosz (2018) [4] explained that a modern, hyper-competitive market of logistics services, with new entrants including those from technology and automotive industries, as well as consumers implies that the incumbents should undergo transformation and develop innovative business models. In the case of logistics industry leaders, digital business models are most often a supplement to traditional, already proven models, which results in hybrid solutions. This suggests how the businesses can build their own models while setting up the digital transformation projects. Prockl, G., et al (2012) [5] had modelled which add value for the 3PL service providers. And, the businesses have to understand it and realize that the digital transformation or technologies help greatly in achieving the business value. Brynjolfsson, E., \& McAfee, A. (2012) [6] found that the more technology an industry had, the more intense competition within it became. - the top performers-were racing ahead of the rest to explore and exploit new technology-enabled business models. They were homesteading on a digital frontier, opening up new territory that others would eventually settle in. As the industry is learning from the other providers and competitors in the market who have already adopted these digital technologies, gives the confidence and comfort to others in the market. Delfmann, W. et al (2002) [7] had identified the two major changes induced by e-commerce, which were disintermediation and the upcoming electronic marketplaces. For both changes, the authors have specified the logistically relevant drivers. These are for electronic market places; the duration of relationships, the geographical dispersion of customers and vendors, the type of goods traded at emarketplaces and the type of contracts which are concluded. This tells that the digital is greatly disturbing the industry. European Commission (2016) [8] explained that the Digital transformation is characterized by a fusion of advanced technologies and the integration of physical and digital systems, the predominance of innovative business models and new processes, and the creation of smart products and services. The digital transformation of EU business and society presents enormous growth potential for Europe. European industry can build on its strengths in advanced digital technologies and its strong presence in traditional sectors to seize the range of opportunities that technologies such as the Internet of Things, big data, advanced manufacturing, robotics, 3D printing, block chain technologies and artificial intelligence offer. This will enable the industry to capture a share in the emerging markets for the 
products and services of the future. Kayikci, Y. (2018) [9] described that the key promises of this Digital technologies concept are enabling real-time full-transparency from suppliers to customers, small lot sizes, multiple product variants, connected processes and decentralized, autonomous management. This study highlights the benefits of the digitization of logistics process and examines the sustainability impact of digitization in logistics. Osterwalder, A., \& Pigneur, Y. (2010) [10], developed the Business model generation techniques for every business. And, this can be modeled for Logistics and Supply chain business as well and to implement the Digital technology in particular into the Logistics and Supply chain system implementation. Paprocki W. (2017) [11] detailed out that the Transport and logistics operators take up the gauntlet of fundamental transformation of their activity in order to fulfill the challenge of the Fourth Industrial Revolution. The participants of the supply chain anticipate that their business partners will use the same technologies and adjust their business models to the changing demands of their customers.

\section{DIGITAL TRANSFORMATION IN LOGISTICS AND SUPPLY CHAIN}

As it is evident to know that Logistics is a core and key integral component of a Supply chain in ensuring delivering the right product, right time at right cost. And, IT systems, the Warehouse Management System (WMS), in particular help the Logistics business greatly in achieving the same.

Prior to any IT Systems or WMS, the logistics businesses were full of paper based and all of its where manual labor operations performed. Both were pretty expensive, time consuming, labor intensive and easy error prone. And, some of the very common issues that the Logistics industry faced when there was no WMS system were;

- No inventory visibility - no business partner including the warehousing personnel in the logistics and supply chain could see the current inventory at the facility

- $\quad$ Shipment processing errors - over shipping, under shipping, miss-shipping

- Warehouse space utilization issue - warehouse space underutilization and/or over utilization

- Manual and Paper work - lots of paper work to be done and maintained for auditing purposes in addition to performing all the warehousing work manually

- Safety Issues - Since there was no IT systems or any technological device used, it has caused safety issues at situations such as handling hazmat items, heavy items, special handling items etc.

When the Technology had started evolving few decades ago, it had contributed to the Logistics and Supply Chain as well to enjoy the benefits. And, as everyone could evidence that the industry is seeing tremendous advancements in the technology area in the last decade or so, it is contributing to the Logistics systems as well.

Warehouse Management System (WMS) is a great tool or application that helps the Logistics business to manage the inventory effectively and efficiently. And, it helps tremendously in providing the inventory visibility to all the business stakeholders.
The latest advancements in the digital technology field are also contributing to the WMS Implementations concurrently where WMS application is integrated with these digital technologies. This is due to the fact that the customer expectations are changing as these digital technologies are being evidently seen as the following primary value adds to their business;

$$
\begin{aligned}
& \text { * Increasing Warehouse productivity } \\
& \text { * Seamless Electronic communications } \\
& \text { * Providing Dashboards } \\
& \text { * Real-time Inventory / Business Data }
\end{aligned}
$$

Below are some of the key digital technologies that have been recently contributing to the Logistics business thru WMS implementations, where these are integrated with WMS system or application for different reasons as detailed above.

$\begin{array}{ll}\checkmark & \text { Automation such as Conveyors etc } \\ \checkmark & \text { Robots } \\ \checkmark & \text { Drones } \\ \checkmark & \text { AGVs } \\ \checkmark & \text { AS/RS } \\ \checkmark & \text { Automated Picking Tools such as Pick-to-Light, } \\ & \text { Voice picking etc. }\end{array}$

\section{A CASE STUDY ANALYSIS}

This case study has been conducted in a leading logistics and supply chain company to evaluate and understand the role of Digital technologies in a Distribution Center where the Warehouse Management System is managing the warehouse processes end to end and provides better inventory visibility to all the stakeholders. And, this company has been implementing different type of WMS application based on their customer and business requirements.

This study was conducted in a Warehousing and Distribution facility that has implemented the Tier-1 WMS due to the business complexity. And, based on the data collection thru project documentations and observations from the warehousing / distribution facility, it is found that the below key factors are contributing to the success of the Logistics business in the recent technological advancements thru WMS implementations;

1. RF Handheld devices / Vehicle Mounted Units (VMU) - these devices help performing the day to day warehouse activities much more faster and with very low user error. As, these are integrated with the WMS, it helps in validating the data that the user is attempted to scan from the product. The facility has seen a $65 \%$ improvements in lead time in performing the warehouse activities such as receiving, picking, packing, shipping and cycle count while using these devices against the mode where there is no RF / VMU devices. And, the user error has come down to $3 \%$ from its $12 \%$.

2. Automation - the Conveyors were being used at this facility for processing the packages $-48 \%$ increase in volume in processing the packages. These Conveyors have the barcode scanners and the integrated with WMS that speed up the processing time of the packages and also improve the accuracy of the product handling per business requirements. 
3. Trailer Management - Managing the trailers at both Inbound and Outbound $-37 \%$ reduction in erring transactions in managing the trailers on the yards. The Scanners were installed at the dock which helps to track the trailers and ensure the right yard slots / dock doors are assigned to it and also provide the carriers and the warehouse users the visibility on these trailers.

4. Customer Visibility - Real time and seamless $42 \%$ increase in communication speed against the traditional modes. This provides the customer insights into the Logistics systems and not just to see real-time how the warehouse is performing but also to understand how the business is performing in the market as well and thus helps in better planned forecasting.

5. Flexibility and Productivity - work from anywhere, anytime and any device - new and advanced digital technologies help organizations to run their businesses anywhere from the world and by using different digital devices and with round the year business model with no down time. This increased the workforce productivity by $18 \%$ in this facility that has implemented this digitized model. As the WMS application was hosted on the Cloud, there was no down time required for any system maintenance.

6. Dashboard - KPI reporting - $38 \%$ time savings in getting these KPI reports as opposed to manual report generation techniques. These digital technologies help to represent the business behavior in a very interactive and user-friendly manner. It is not only helping the management to report the data to the business stakeholders but also identify the opportunities to improve the areas where it lags.

7. Inventory Tracking - The RFID technology is helping to track the high value items in the facility. Every movement of these items are tracked from receiving thru shipping. This study shows that there is a $29 \%$ increase in speed in tracking such items.

8. Data Analytics - data analytics tool - this tools helps both the customer and the Logistics service provider to understand and forecast the market behavior from the Logistics business model and align the warehouse resources accordingly at any given season or period. This provides the flexibility for the customer to extract the data as needed and analyze it for their internal purposes.

9. Advanced solutions - Robots and Artificial Intelligence $-51 \%$ increase in speed in processing. This study finds that the warehouse is using the Robots and Artificial Intelligence for moving the packages from once place to another to be able to sort them with no error and to run the business continuously with no interruption.

These are the major benefits that the business enjoys due to digital transformations in the WMS implementations in the recent times in this specific facility where this research was conducted.

\section{CONCLUSION}

It is proven already by many researchers and industrialists that these digital technologies are immensely helping the global community in general and thus greatly contributing to the Logistics business as well. In this research, it is evident that this Logistics service provider is enjoying the benefits of having these digital technologies incorporated in their WMS implementations, based on the findings detailed out in each of the area that it is contributing to.

This research study specifically focuses on the latest digital technological developments or changes in the WMS implementations area at a specific Warehousing / Distribution facility where the business model is complex and a Tier-1 WMS application is implemented. And, how these technologies helped this facility when they were integrated with WMS application.

This research can be extended to multiple facilities and that may use different type of WMS applications for further scope and analysis. This can also be extended to analyze the challenges at the facility during and after these digital technologies adopted in WMS implementations.

\section{REFERENCES}

[1] MIT Center for Digital Business and Capgemini Consulting (2011). DIGITAL TRANSFORMATION: A ROADMAP FOR BILLION-DOLLAR ORGANIZATIONS.

[2] WEF (2016), Digital Transformation of Industries: Logistics Industry [White paper]. World Economic Forum \& Accenture.

[3] PwC (2016), Industry 4.0. How digitalization makes the supply chain more efficient, agile, and more customerfocused, PwC. Retrieved Sep 15, 2018 from https://www.strategyand.pwc.com/report/digitizationmore-efficient

[4] Marzenna Cichosz, Digitalization and Competitiveness in the Logistics Service Industry, "e-mentor" 2018, No 5(77), pp. 73-82, http://dx.doi.org/10.15219/em77.1392.

[5] Prockl, G., Pflaum, A., \& Kotzab, H. (2012), 3PL factories or lernstatts? Value-creation models for 3PL service providers. International Journal of Physical Distribution \& Logistics Management, 42(6), 544-561.

[6] Brynjolfsson, E., \& McAfee, A. (2012). Race against the machine: How the digital revolution is accelerating innovation, driving productivity, and irreversibly transforming employment and the economy. Lexington, MA: Digital Frontier Press.

[7] Delfmann, W., Albers, S., \& Gehring, M. (2002). The impact of electronic commerce on logistics service providers. International Journal of Physical Distribution \& Logistics Management, 32(3), 203-222.

[8] European Commission (2016). Digital transformation, Retrieved Sep 15, 2018 from http://ec.europa.eu/growth/ industry/digital-transformation_en

[9] Kayikci, Y. (2018), Sustainability impact of digitization in logistics. Procedia Manufacturing, 21, 782-789.

[10] Osterwalder, A., \& Pigneur, Y. (2010), Business model generation: a handbook for visionaries, game changers, and challengers. New Jersey: John Wiley \& Sons.

[11] Paprocki W. (2017) How Transport and Logistics Operators Can Implement the Solutions of "Industry 4.0" 